\title{
Gerardo Valencia Cano, obispo de los pobres*
}

\section{Antonio José Echeverry-Pérez ${ }^{* *}$ David Mauricio Bernal-Argote ${ }^{* * *}$}

RECIBIDO: 25-04-16. APROBADO: 31-10-16

Resumen: La vida y obra de Gerardo Valencia Cano es bien reconocida en los lugares donde su figura delgada se hizo presente, es decir, Yarumal, Mitú y Buenaventura. A pesar de que su obra pastoral y misional fue prolífica en estas comunidades, son pocos los textos que exploran de manera profunda y reflexiva sus proyectos, así como su trabajo intelectual, literario, teológico y eclesial. Sin embargo, nuevas aproximaciones, diferentes perspectivas y un trabajo documental serio permiten evidenciar que la figura de monseńor Valencia Cano ofrece una multiplicidad de acercamientos y que su vida agitada como miembro de la Iglesia Católica del siglo XX supone intersticios todavía vírgenes para las ciencias sociales.

Palabras clave: Gerardo Valencia Cano, espiritualidad, misiones, episcopado colombiano, teología de la liberación, Golconda.
Gerardo Valencia, the Bishop of the Poor

Aвstract: The life and work of Gerardo Valencia Cano is well known in Colombian places where he was present, like Yarumal, Mitu and Buenaventura. Despite his prolific pastoral and missionary work in these communities, just few works explore his projects and his intellectual, literary, theological and ecclesial works in a deep and thoughtful way. However, new approaches, different perspectives and a serious documentary work show that the figure of Bishop Valencia Cano offers a multiplicity of approaches and also that his hectic life as a member of the Catholic Church of the 20th Century entails unspoiled gaps for the social sciences.

Key Words: Gerardo Valencia Cano, Spirituality, Missions, Colombian Episcopate, Liberation Theology, Golconda.

\section{PARA CITAR ESTE ARTÍCULO:}

Echeverry Pérez, Antonio José y David Mauricio Bernal Argote. "Gerardo Valencia Cano, obispo de los pobres". Theologica Xaveriana 184 (2017): 361-385. https://doi.org/10.11144/javeriana.tx67184.gvcop

* Artículo producto del proyecto de investigación de convocatoria interna de la Universidad del Valle, Facultad de Humanidades, Departamento de Historia (5 de junio de 2013 a 5 de junio de 2015) titulado "Gerardo Valencia Cano. Un profeta invisibilizado (1950-1970)".

"* Antonio J. Echeverry: Doctor en Historia de América. Profesor titular, Universidad del Valle. Director del grupo de investigación "Religiones creencias y utopías", reconocido y categorizado por Colciencias. ORCID: 0000-0001-5479-8132. Correo electrónico: antonio.echeverry@correounivalle.edu.co/ ** David M. Bernal: Historiador, Universidad del Valle. Integrante del Semillero del Hecho Religioso adscrito al grupo de investigación "Religiones, creencias y utopías", Universidad del Valle. Orcid: 0000-0003-1806-4021. Correo electrónico: david.bernal@outlook.es 


\section{Introducción}

Hace cien años, el 26 de agosto de 1917, nace Gerardo Valencia Cano, en Santo Domingo, Antioquia, quien habrá de convertirse paulatinamente en una figura sobresaliente en la apenas incipiente "nueva Iglesia" latinoamericana; esto, mientras ejerce como misionero del Instituto de Misiones Extranjeras de Yarumal, prefecto apostólico de Vaupés (1949-1953), miembro participante del Concilio Vaticano II (1962-1965), presidente del Departamento de Misiones de Celam (1966), director del Centro Antropológico Colombiano de Misiones, Ethnia (1966) y vicario apostólico de Buenaventura (1953- 1972).

Valencia Cano es una figura religiosa sobresaliente entre 1950 y 1972, al gestar importantes proyectos sociales y educativos ${ }^{1}$ para los pobres $^{2}$ y ser un significativo crítico de los problemas que aquejaban nuestro país, lo cual se denota ávidamente al participar en la II Conferencia General del Episcopado Latinoamericano realizada en Medellín, en 1968, donde se manifiesta: “...se impone un cambio de estructuras, pero no se debe acudir a la violencia armada y sangrienta que multiplica los problemas humanos, ni a la violencia pasiva inherente a las estructuras actuales que deben ser modificadas"3.

De tal Conferencia sale referenciándose a sí mismo como un "obispo socialista y revolucionario", alusión que se hace constante durante su participación en el movimiento sacerdotal Golconda ${ }^{4}$ (1968-1972), hasta el día de su trágica muerte en un accidente aéreo, el 21 de enero de 1972, a bordo de un avión de la compañía Satena, el mismo año en el que se disuelve el grupo de los "curas rebeldes"s.

Aunque eclipsado por la obra de representantes de gran envergadura de la Iglesia Católica, como Gustavo Gutiérrez, Hélder Câmara, o Camilo Torres Restrepo, la trayectoria de Valencia Cano dista de ser opaca.

\footnotetext{
${ }^{1}$ Entre los colegios y demás entidades fundados por Valencia Cano en Buenaventura, encontramos los siguientes: la Escuela Industrial, el Orfanato San Vicente de Paúl, la Normal Superior Juan Ladrilleros, el Hogar Jesús Adolescente, la Escuela de Artesanías del Pacífico, la Normal Práctica Popular y el Instituto Matías Mulumba.

2 Para mayor información, ver: "Balance de obras en el Vicariato Apostólico de Buenaventura", Buenaventura, 31 de diciembre de 1961. En: Archivo de la Diócesis de Buenaventura.

${ }^{3}$ Restrepo, La revolución de las sotanas, 34 .

${ }^{4}$ El grupo sacerdotal Golconda nace en una finca ubicada en Viotá, Cundinamarca, llamada con ese nombre. Logra consolidarse gracias al interés de un grupo de sacerdotes por reflexionar acerca de las problemáticas sociales de la Iglesia y el estudio de documentos de vanguardia de la misma, como fue la encíclica Populorum progressio (1967), de Pablo VI.

${ }^{5}$ Para mayor compresión de la expresión, ver a Muniproc, Golconda, el libro rojo de los “curas rebeldes", 140.
} 


\section{Planteamiento de la cuestión}

Los párrafos siguientes muestran, por medio de reflexiones propias del prelado, un aspecto fundamental para conocer con mayor detalle al "obispo rojo" o al "hermano mayor"': su relación con Dios (espiritualidad). No se propone hacer una profunda reflexión teológica sobre su vida, sino identificar los rasgos más característicos de su espiritualidad, que son los que enmarcan su presencia misionera en el país y su influjo a nivel latinoamericano.

A partir de sus oraciones, las notas de su diario personal, artículos, discursos, sermones y alocuciones radiales se han podido identificar cinco dimensiones desde las que se configura su espiritualidad: la santidad, el recogimiento, la oración, el abandono a la voluntad del Dios y la pobreza. El orden aleatorio en el que se presentan aquí no expresa sus niveles de importancia, sino tiene el propósito metodológico de analizar cada uno de estos componentes. Estos tampoco tienen, en estricto sentido, orden cronológico ${ }^{7}$ son dimensiones complementarias todas que se van profundizando con el paso de los años. Este acercamiento ha sido posible principalmente por un texto de oraciones escrito por el mismo Gerardo Valencia Cano y publicado en 1965, poco conocido, que se acopia por la gentileza de la Unión de Seglares Misioneras, Usemi. Aunque esta primera fuente es privilegiada para el presente artículo, se complementa la información con la ayuda de su principal biógrafo Gerardo Jaramillo González $z^{8}$, quien ha logrado poner a disposición del público gran parte del diario del "obispo de los pobres", y al trabajo de archivo ejecutado en la diócesis de Buenaventura, la vicaría apostólica de Vaupés y los testimonios de varios de los seguidores de monseñor Valencia Cano. Se ha realizado una triangulación entre estas fuentes para garantizar un acercamiento lo menos subjetivo posible.

\section{Un acercamiento contextual}

La gran coyuntura en la que se desenvuelve el "hermano mayor" se localiza entre los años 40's y 70's del siglo XX, época marcada por la posguerra, tres décadas que se caracterizan por profundas transformaciones sociales, económicas, políticas y cultu-

\footnotetext{
${ }^{6}$ Se utiliza un apelativo u otro dependiendo de dónde proceda la referencia. Para la prensa sensacionalista fue el "obispo rojo", mientras que para los pobladores pobres del puerto de Buenaventura fue su "hermano mayor".

${ }^{7}$ Vale la pena aclarar que, si bien las dimensiones son complementarias y se pronuncian en el prelado sin un orden cronológico, se puede inferir que el grueso de su vida espiritual inicia con su formación en el Seminario de Misiones Extranjeras de Yarumal, en el amanecer de la década del 40, y termina en 1972, cuando oficia como Vicario Apostólico de Buenaventura.
}

${ }^{8}$ Jaramillo González (ed.), Monseñor Valencia, 158-214. 
rales. Para Hobsbawm, después de la segunda Guerra Mundial, "siguió un periodo de 25 o 30 años de extraordinario crecimiento económico y transformación social, que probablemente evolucionó la sociedad humana más profundamente que cualquier otro periodo de duración similar"'.

A partir de la segunda mitad del siglo XX se evidencia un sentimiento generalizado por nuevas búsquedas, y las perspectivas tecnocráticas y desarrollistas de los ańos 40 y 50 se interrumpen abruptamente ${ }^{10}$. La Alianza para el Progreso ${ }^{11}$ y la Fundación Panamericana de Desarrollo son respuestas de los Estados Unidos, cuya cabeza visible es John F. Kennedy, con las que ese país intenta salir al paso al sentimiento revolucionario que ha quedado a raíz de la experiencia de insurrección en Cuba (1959). Reformas y no revolución es la consigna que el país del Norte pretende implementar ${ }^{12}$.

Por otra parte, el contexto nacional de la segunda mitad del siglo XX está matizado por conflictos políticos entre liberales y conservadores, intensificados a partir del magnicidio del líder liberal Jorge Eliecer Gaitán, el 9 de abril de 1948. Las regiones más golpeadas por este flagelo son la Andina y los Llanos Orientales, debido a la concentración de bandas conservadoras en la primera y liberales en la segunda $^{13}$. La lucha bipartidista continúa hasta el establecimiento de la coalición política concretada en 1958 por los partidos Liberal y Conservador, conocida como Frente Nacional (1958-1974), pacto mediante el cual el poder presidencial se alternará, cada cuatro ańos, entre estos dos partidos.

Con el Frente Nacional como preludio, en los albores de la década del 60 se distinguen protestas sociales en diferentes lugares del país. Lo más llamativo es la participación del clero en dichas manifestaciones. Tal es el caso del clero caleño, que se compromete con la protesta social en la capital del Valle del Cauca, dada en torno de las alzas en el sistema de transporte, en 1968 hecha visible en declaración previamente consultada con el arzobispo, monseñor Alberto Uribe Urdaneta. En ella, tras un análisis de la situación, los miembros del clero caleño reclaman y exigen al

\footnotetext{
${ }^{9}$ Hobsbawm, Historia del siglo XX, 15.

${ }^{10}$ De Roux, "Religión y revolución", 174-175.

${ }^{11}$ La Alianza para el Progreso tuvo como objetivo general "mejorar la vida de todos los habitantes del continente". Es el programa de ayuda externa propuesto por Estados Unidos para América Latina con el fin de crear condiciones para el desarrollo y la estabilidad política en el continente durante los años sesenta. Con este programa, Estados Unidos inaugura un tipo de intervención sistemática, de largo plazo y a escala regional, con miras a orientar el cambio social en América Latina e impedir el avance del comunismo en el marco de la Guerra Fría (Rojas, "Alliance for Progress in Colombia").

${ }^{12}$ De Roux, "Religión y revolución”, 174-175.

${ }^{13}$ Betancourt, y García, Matones y cuadrilleros. Origen y evolución de la violencia en el occidente colombiano, 217.
} 
gobierno la reconsideración de dichas alzas, al tiempo que rechazan la violencia en todos los aspectos ${ }^{14}$.

Otro ejemplo lo presenta el clero de Barranquilla, capital del Atlántico, al protestar contra las tarifas en el transporte, uniéndose con el pueblo en busca de reivindicaciones que satisfagan sus reclamos ${ }^{15}$.

Y algo similar ocurre en Medellín.

En su obra Medellin (rojo), Oscar Calvo Isaza y Mayra Parra Salazar describen el final de la década de los años 60 como una lucha de los grupos sociales (sacerdotales, estudiantiles, obreros, sindicalistas) contra el esfuerzo gubernamental de apaciguar las protestas en torno de la situación del país ${ }^{16} \mathrm{y}$ hablan de un esfuerzo acérrimo del gobierno por "maquillar" la ciudad que en agosto de ese año habría de recibir a la II Conferencia General del Episcopado Latinoamericano.

Como se podrá evidenciar más adelante, las acciones del obispo en Buenaventura en favor de las familias desplazadas por la ampliación del muelle marítimo del puerto de Buenaventura, se inscriben claramente en todo este contexto ${ }^{17}$.

Por su parte, la Iglesia Católica entra en armonía frente a los procesos de cambio y vive, en este mismo periodo, condiciones similares de transformación de su pensamiento. Esta dinámica parte de las cartas encíclicas Quadragesimo anno (1931), sobre la restauración del orden social, y Divini Redemtoris (1937), de Pio XI, y pasa -por supuesto- por la primera reunión del Celam en Río de Janeiro (1955), por las cuatro sesiones del Concilio Vaticano II (1962-1965) ${ }^{18}$, la encíclica Populorum progressio (1967) y el manifiesto "Revoluciones para el bien común" encabezado por Hélder Câmara, arzobispo de Recife, Brasil, del 15 de agosto de 1967, hasta llegar a la visita del papa Pablo VI a Colombia y la Conferencia del Episcopado Latinoamericano en Medellín (1968).

Esta Iglesia, que en la encíclica de 1937 manifiesta grandes preocupaciones por el "comunismo ateo" ${ }^{19}$, termina este proceso de transformación con Medellín, y en 1968 planteará:

\footnotetext{
${ }^{14}$ Echeverry, Teología de la liberación en Colombia, un problema de continuidades en la tradición evangélica de opción por los pobres, 260.

${ }^{15}$ Ibíd.

${ }^{16}$ Calvo y Parra, Medellín (Rojo) 1968, 172.

${ }^{17}$ Echeverry, Gerardo Valencia Cano. Un profeta invisibilizado, 25-31. En este texto se desarrolla en detalle el trabajo del obispo tanto en el Mitú como en Buenaventura.

${ }^{18}$ Cabe recordar que monseñor Gerardo Valencia Cano participó en las cuatro sesiones del Concilio Vaticano II: 1962, 1963, 1964 y 1965.

19 "Este peligro tan amenazador, como habréis comprendido, venerables hermanos, es el comunismo bolchevique y ateo, que pretende derrumbar radicalmente el orden social y socavar los fundamentos mismos de la civilización cristiana" (Pio XI, "Carta encíclica Divini Redemptoris sobre el comunismo ateo (1937)".
} 
La Iglesia ha buscado comprender este momento histórico del hombre latinoamericano a la luz de la Palabra, que es Cristo [...] estamos en el umbral de una nueva época histórica de nuestro continente, llena de un anhelo de emancipación total, de liberación de toda servidumbre, de maduración personal y de integración colectiva... ${ }^{20}$

Y en el obispo misionero Gerardo Valencia Cano encontramos al hombre que, como sacerdote, se esfuerza por responder a esos tiempos, a esos procesos de transformación. Se propone ahora, una caracterización de su derrotero espiritual.

\section{La espiritualidad en Gerardo Valencia}

Cano: articulación de cinco variables

Se trata aquí de hacer una aproximación histórica de su espiritualidad -asunto del que poco se han ocupado los historiadores de la Iglesia y los teólogos-, más que hacer una reflexión teológica profunda sobre su vida espiritual; esto es, de identificar y caracterizar, a partir de las fuentes, las dimensiones en las que se enmarca el itinerario espiritual de monseñor Valencia Cano.

\section{La santidad}

La carta de la undécima Conferencia Episcopal de Colombia (1944) a los venerables párrocos de la República, de cara al problema social de la nación, recordará el mandato expreso de Pio XI (en Divini Redentoris): “...el medio más eficaz del apostolado entre las muchedumbres de los pobres y de los humildes es el ejemplo del sacerdote, el ejemplo patente y ostensible de todas las virtudes sacerdotales" ${ }^{21}$.

Se tiene la certeza de que la espiritualidad del obispo Valencia se enmarca en esta exigencia pontificia que es, en términos teológicos, un proyecto de santificación ${ }^{22}$. Su vida está centrada en la configuración de tal propósito, y no podrá entenderse nada en él que no pase por esta premisa. Y el 2 de marzo de 1946, con solo 26 años de edad, tras concluir la Licenciatura en Teología, en la Pontificia Universidad Javeriana de Bogotá, y dar inicio a la prefectura ${ }^{23}$ del Seminario Mayor de Yarumal, expone con mayor claridad este plan:

${ }^{20}$ Celam, "II Conferencia General del Episcopado Latinoamericano. Documentos finales de Medellín": Introducción 7.

${ }^{21}$ Conferencia Episcopal de Colombia, Conferencias Episcopales de Colombia, Tomo I, 1908-1953, 80.

${ }^{22}$ En la tradición cristiana, el concepto proviene del latín sanctus, del griego óyíos, o del hebreo qadoš, que significan el "elegido por Dios", o "diferenciado", "distinguido".

${ }^{23}$ Uno de los cargos de mayor responsabilidad en el Seminario. 
Hace mucho tiempo, divino Maestro de mi alma, viene dibujándose en mi mente el ideal de mi santidad. Sin duda alguna es tu mano divina la pintora. Lo he buscado en los libros y en los hombres, mas esta es la hora en que no lo he hallado. ¿Dónde está? ¿'Será acaso que mi exigente orgullo y una diabólica vanidad me invitan a soñarme el mejor de los hombres, modelo sin modelo? [...] yo quiero, como Santa Teresita, ser un gran santo. ${ }^{24}$

No obstante, la búsqueda de monseñor Valencia de esa eutopía ${ }^{25}$ necesita aún más definiciones: ¿Cuál es el modelo a seguir? Él ya ve, autocríticamente, que el modelo no es él mismo, por lo que decide proponerse un modelo, una guía:

Ser: supremamente serio, con mucha bondad; grave y alegre y jovial; piadosísimo sin afectación: puntualísimo, con naturalidad; ordenado y culto, sin vanidad ni amaneramientos; purísimo, con mucha prudencia hacia los pecadores; estudiosísimo, sin exceso; celosísimo cumplidor del deber con tacto para medir las circunstancias; mortificadísimo, procurando no obstante estar bien para servir mejor a mi Dios. ${ }^{26}$

Como puede observarse, es un modelo exigente, muy humano pero eutópico, que será imposible alcanzar en su plenitud, pero importante, porque le permitirá mejorar cada día en su proyecto de santidad y, después de 24 años de búsqueda, será él mismo a ocho días de su fatídico accidente, quien reconocerá:

Jueves 13 de enero de 1972

Escribir frases intrascendentes [...] ¿qué importa? Me interesa hacerme presente cada mañana a una cita especialísima, en la que no obstante su especialidad, yo no puedo alcanzar una pulgada por encima del suelo porque soy tierra, fango y maldad. Solo el santo puede volar. Yo, qué lejos estoy de serlo. Así que preparo en estas páginas la tierra con que me sepultarán en el olvido. ${ }^{27}$

En estas líneas, monseñor Valencia parece hacer ya un balance final de su vida, la misma que ha estado marcada -como puede observarse- por la premisa inalcanzable de "ser un gran santo". Este es un ideal o concepto que ha delineado su obraje. "Serio, alegre y jovial": así es reconocido el obispo que ha sido aceptado como parte de la cotidianidad de las personas que lo circundan. Así ha ocurrido en Mitú (1949-1953) y en Buenaventura (1953-1972).

\footnotetext{
${ }^{24}$ Jaramillo González (ed.), Monseñor Valencia, 166.

${ }^{25}$ Hablamos de eutopía en el sentido de mejor o perfecto lugar. Vale la pena recordar que el prefijo "u" no existe en el griego. La otra posibilidad es "ou", que indica no existencia y no recoge el sentido de la propuesta de Gerardo Valencia Cano.

${ }^{26}$ Jaramillo González (ed.), Monseñor Valencia, 166.

${ }^{27}$ Ibíd., 188-189.
} 


\section{El recogimiento}

La segunda característica de la espiritualidad del obispo Valencia Cano está marcada por el "recogimiento" continuo e inquebrantable: "He trabajado mucho para tu gloria, pero me he alejado de ti porque no he sufrido por recogerme y estudiar..." 28 . El recogimiento es condición necesaria para orar, para contemplar, para dialogar, aunque sea en silencio: “...cierro los ojos para ver si te encuentro" 29 . Su diario es un encuentro íntimo con Dios, una "plática" permanente con la divinidad. En uno de sus escritos $\left(\sin f_{e c h a}{ }^{30}\right)$, nos habla de este diálogo con Dios:

¡Dialogar con Dios! Gracias, mil gracias. ¿Contigo? Sí contigo. / Yo he oído los grillos y las ranas dialogar con la noche y las estrellas y la luna. / Y pasan las horas dialogando. Y la aurora los halla dialogando. / Los grillos y las ranas con la noche y las estrellas y la luna. / [...] Dios mío perdóname y haz que no te ofenda más, para que mi dialogo contigo sea siquiera como el de los grillos y las ranas con la noche y las estrellas y la luna. ${ }^{31}$

Otro de sus escritos, sin clara datación tampoco, complementará lo que se viene diciendo: "Gracias. Dios mío por la luz. Cómo quisiera, mi dulce Dios, comenzar desde ya esta vida privilegiada de algunos santos" ${ }^{2}$.

Para Valencia Cano, el recogimiento es el ambiente indispensable para escuchar a Dios ${ }^{33}$. El 20 de septiembre de 1951, ya como prefecto apostólico del Mitú, dice: "Dios mío, estoy demasiado distraído para pensar en recogerme [...] en una ciudad que es un hervidero de huelgas y en un mundo convulsionado por el afán de lujuria y el temor de la guerra" ${ }^{4}$. Considera que, sin recogimiento, no habrá "efecto espiritual para las almas" ${ }^{35}$; y concluye: "Necesitamos el recogimiento que es el ambiente indispensable para escuchar a Dios"36. El progresivo y acelerado crecimiento demográfico que vive el país en ese momento es reflejado por el nobel obispo, al señalar que entre 1951 y 1964 las tasas alcanzan el 32 por mil $^{37}$.

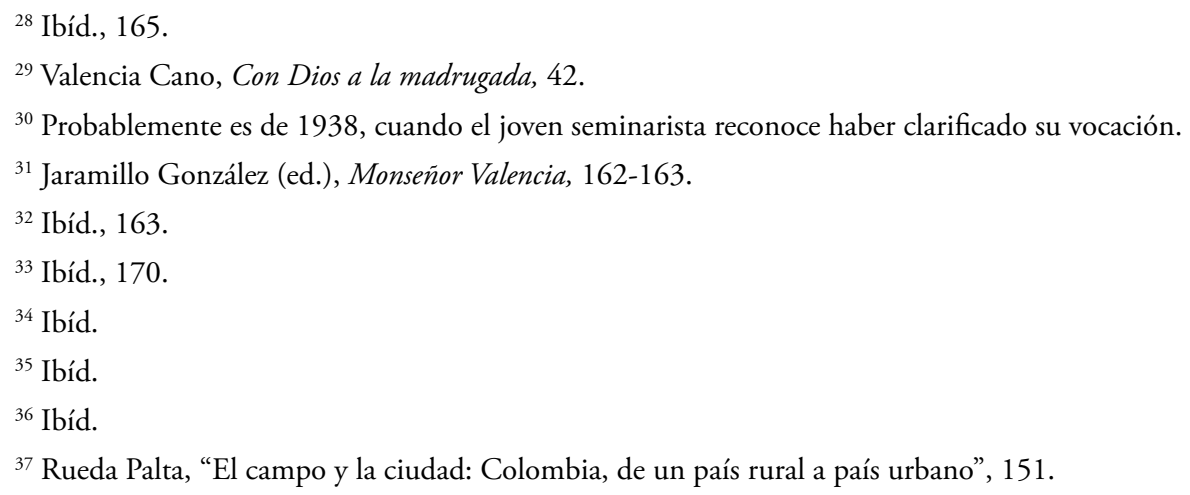




\section{La oración}

El "recogimiento" en Valencia Cano, como condición indispensable para entrar en oración, es la tercera característica distintiva de su espiritualidad. Para empezar, debe afirmarse que en él no hay una conciencia de saber orar; por el contrario, manifiesta permanentemente que no sabe hacerlo: “¿Moriré sin aprender a orar? Así parece. Conozco muchas reglas y métodos; sin embargo, heme aquí como cuando comencé hace ya casi treinta año" "38. Sin embargo, ¿qué es la oración para el obispo? Nuevamente, dejemos que sea él mismo quien responda:

Comunicarse con Dios, en una forma informal sin ritos, sin formulas, hasta sin respeto, en la forma en que cualquier muchacho lo hace con su papá.

Orar es algo que todo el que tiene fe puede fácilmente hacer aunque no sepa el Catecismo o no haya aprendido a leer. Para orar solo se necesita advertir a Dios y querer hablarle.

En la oración, todos somos iguales ante Dios, ricos y pobres, buenos y malos, el solo hecho de orar pone a Dios favorable a nosotros.

Es preciso advertir que con frecuencia las novenas o las plegarias aprendidas de memoria no son oración. La verdadera oración que demuestra la fe de la persona es la oración inventada, espontánea. ${ }^{39}$

Para Valencia Cano, la oración es la expresión indispensable de la fe:

El que no cree no puede pasarse sin orar. Quien no ora es porque no tiene fe. Cristo ordenó a sus seguidores orar siempre y no desfallecer en la oración. Un defecto de muchísimos cristianos de hoy es la falta de oración [...] esto en realidad lo que demuestra es que no saben lo que significa creer. Porque basta con que una persona crea para que le sea indispensable la oración [...] el hombre que advierte a Dios delante [...] que al mismo tiempo descubre el desafío que es para cada ser humano este mundo tan complejo no puede dejar de comunicarse con Dios... ${ }^{40}$

Su oración es un diálogo abierto con Dios, para pedir, agradecer, suplicar, contar, cantar o alabar; es la dimensión donde conversan las angustias con el agradecimiento y las súplicas con los cantares. Veamos un ejemplo:

Yo tan pequeñito como un grillo que apenas se levanta un brinco sobre la yerba, tan despreciable como una rana que croa y salta, pesada y desapaciblemente, quiero dialogar contigo, el altísimo, el Perfectísimo, ipara decirte que

\footnotetext{
${ }^{38}$ Valencia Cano, Con Dios a la madrugada, 11.

${ }^{39}$ Mensaje en el programa radial "Buenos días Buenaventura", 29 de julio de 1971, citado por Jaramillo González (ed.), Monseñor Valencia, 201-202.

${ }^{40}$ Ibíd., 200-201.
} 
he pecado! ¿Qué horror! Que he pasado por encima de tus leyes para complacer mis apetitos y los de otros hombres que no te aman.

Dios mío, perdóname y haz que no te ofenda más, para que mi dialogo contigo sea siquiera como el de los grillos y las ranas con la noche y las estrellas y la luna. ${ }^{41}$

Para comprender de buena manera las vertientes de espiritualidad del obispo es necesario acercarse a su oración. ¿Cómo oraba el obispo Valencia Cano? Nuevamente, son sus diarios los que despejan esta duda. Su oración -como ya se dijo- es un diálogo abierto y ameno con Dios, con su padre, amigo y confidente. Por su alto grado ilustrativo y contenido poético se muestra una oración suya, tomada de uno de sus libros de apuntes:

Señor, cuando yo muera, estos dedos que te escriben, como si fueran lenguas, ya no podrán hablarte con el lápiz o el estilógrafo y se perderán.

Señor, cuando yo muera, estos ojos que se bañan felices en tu luz, como los gansos en el agua, ya no podrán verte y se perderán.

Señor, cuando yo muera, estos pies que han saltado felices como liebres, por los campos y los bosques, ya no podrán portarte como un niño en escarpines y se perderán.

Señor, cuando yo muera, este pecho volcán que tú me diste, ya no reventará como una flor ante cada sonrisa y cada lágrima y se perderá.

Señor, cuando yo muera, ¿qué será de mí? Déjame perderme bajo la tierra, como una pepa dura, de la memoria de todos, mientras que tú plasmas de nuevo al viejo Adán, y reviente como una estrella sobre el nuevo mundo. ${ }^{42}$

No obstante, la oración de Valencia Cano ofrece multiplicidad de perspectivas, y es igualmente ocasión de evaluación, de reflexión para el cambio; son muchas las oraciones desde este aspecto, pero seleccionamos la que hizo 21 días antes de su trágico accidente, el 31 de diciembre de 1971:

Al comenzar a escribir mi última página de este año, siento que fue tan corto que lo puedo estrechar con los dedos de mi izquierda ${ }^{43}$. ¿Qué te daré mi Dios, fuera de gracias...? La mañana se pinta alegre y pacifica como hace 365 días. Tú el mismo. ¿¡Yo... Tú lo sabes, más cerca del fin; señor ten piedad de mí. ¿No lo ves? Aunque puedo coger con una mano las 365 páginas, qué distancia tan grande hay entre unas y otras. En algunas, pocas en verdad, abismo total. En otras, las más, vacíos inmensos. Sin embargo, tengo que agradecerte mi fidelidad. Es quizás el año que menos abismos totales he tenido. Señor, pero quizás en el que más me has hecho comprender mi pasmosa debilidad. Nunca había comprendido más claramente que nada de lo humano me es ajeno. ${ }^{44}$

\footnotetext{
${ }^{41}$ Ibíd., 163.

42 Ibíd., 195.

${ }^{43}$ Se refiere a la cantidad de páginas que tiene su diario.

${ }^{44}$ Jaramillo González (ed.), Monseñor Valencia, 185.
} 
La piedad, la santidad, el recogimiento y la oración son todos procesos que direccionan la vida del "hermano mayor" en torno de un fortalecimiento espiritual que se encuentra intrínsecamente relacionado con la realidad; para él, la oración es la posibilidad de fortalecerse, de tomar confianza. Y termina así su oración de ese 31 de diciembre de 1971:

Señor Dios, padre mío, y por Cristo, de todos los hombres, yo te agradezco de lo más íntimo, la providencia con que a lo largo de toda mi vida -y, quizás más especialmente durante este año- me has dispensado. No me dejes, Señor, de tu mano. Mira cuán débil soy, no me dejes, mi Dios, no me dejes, ten piedad de mí. María, madre mía, y tú, José, acógeme en el seno de tu hogar. ${ }^{45}$

Valencia Cano es profundamente devoto de María madre de Jesús y de San José, su padre. Estas son devociones muy arraigadas en la cultura antioqueña de la primera parte del siglo XX. La comunión con Dios salta a la vista: su obra es el reflejo del diálogo diario con él. Ello supone, como se ha visto, distintos matices y diferentes "colores" en la personalidad del obispo. Su oración es la dimensión que recorre transversalmente su espiritualidad, ya que las otras variables pueden reflejarse en ella.

Para terminar esta vertiente, baste recordar el testimonio que brinda el sacerdote jesuita Gabriel Izquierdo, inmediatamente después del trágico accidente de monseñor Valencia Cano:

Quisiera como epílogo expresar la impresión que me acusó su vida de oración. Muy de mañana y antes de preparar sus programas radiales, "Voz de guía", para Buenaventura, y el "Litoral recóndito", monseñor pasaba un largo rato en oración. Nuestra vida solo se entiende en la fe y el alimento de la fe, además de las obras, es la oración. ${ }^{46}$

\section{Abandono a la voluntad de Dios}

Como es frecuente en la vida de los santos, Gerardo Valencia Cano opta en su vida de fe por una actitud de "abandono a la voluntad del Padre". Son muchas las expresiones en su oración que lo confirman.

Su libro de oraciones, publicado en 1965, inicia con una frase del padre Carlos de Foucauld ${ }^{47}$ : "Orar es pensar en Dios con amor" ${ }^{38}$. No puede pasar desaper-

${ }^{45}$ Ibíd.

${ }^{46}$ Izquierdo, "El hermano que vive entre nosotros. Monseñor Gerardo Valencia Cano", 180-184.

${ }^{47}$ Por ser de magna importancia en la espiritualidad de Gerardo Valencia Cano, se puede consultar una pequeña biografía del padre Carlos de Foucauld elaborada por la Asociación Carlos de Foucauld en España (http://www.carlosdefoucauld.es/HnoCarlos/biografia.htm).

${ }^{48}$ Valencia Cano, Con Dios a la madrugada, 11. 
cibido este detalle, dado que una las grandes características del padre de Foucauld es justamente su actitud de "abandono a Dios". Así lo demuestra la oración que rezan todos los miembros de las comunidades inspiradas por é $\mathrm{e}^{49}$ :

Padre me abandono a ti.

Haz de mi lo que tú quieras.

Por todo lo que hagas de mi te doy gracias.

Estoy dispuesto a todo, todo lo acepto,

con tal que se haga tu voluntad en mi y en todas tus criaturas.

No deseo nada más Dios mío.

Pongo mi vida en tus manos, te la doy Dios mio

con todo el amor de mi corazón, porque te amo.

Es para mi una necesidad de amor el darme,

el entregarme en tus manos sin medida,

con infinita confianza porque tú eres mi padre.50

Para el tiempo de Valencia Cano, el padre Carlos de Foucauld no había sido beatificado ni canonizado (es beato desde el 13 de noviembre de 2005, por Benedicto XVI), pero él es -para el "obispo de los pobres"- un modelo a seguir, y no solo San Francisco de Asís, como lo afirman constantemente sus biógrafos: “Tenía, pues, Gerardo mucho de dónde aprender amor a la pobreza, a la pobreza con la cual se abrazó durante toda su vida, en forma muy parecida a la del Poverello de Asís"s1.

Valencia Cano es un hombre que vive pendiente de Dios, para no ofenderlo, ve continuamente a Dios en la circunstancias, y está obsesionado con su amor. Agradece cotidianamente por sus beneficios. El 10 de noviembre de 1942, a menos de veinte días de su ordenación sacerdotal, en su oración diaria, dice:

No me dejes, no te pierdas a mis ojos, ni permitas que se extingan en mis venas el vigor de tu sangre. Jesús mío, quiero vivir de tu vida y no hacer sino lo que tú quieras; para eso me deposito en las manos de mis superiores como en las tuyas propias para no tener más voluntad que la de no tenerla propia. Quítame Jesús mío la libertad de ofenderte.52

Resulta por lo menos extrańo encontrar en el "obispo de los pobres" una actitud tan sumisa, no solo a la "voluntad del Padre", sino en igual medida a sus superiores,

\footnotetext{
${ }^{49}$ Hermanos de Jesús, Hermanos del Evangelio, Hermanitas de Jesús y Fraternidades Laicas.

${ }^{50}$ De Foucauld, "Oración del abandono".

${ }^{51}$ Jaramillo González, El obispo de los pobres: una biografía de Gerardo Valencia Cano, 17.

52 Ídem (dir.), Monseñor Valencia, 104.
} 
en los que identifica la "voluntad de Dios"; es la actitud propia de quien quiere caminar en humildad a la santidad. De ahí su súplica permanente: "Señor Jesús enséñame la humildad, la mansedumbre y el amor necesarios para hacer lo que quieres de mi" ${ }^{3}$. En este mismo sentido "escuchemos" sus palabras escritas diez años más tarde, el 22 de octubre de 1952:

Hoy quiero insistir en que me organices de modo que yo no haga mi voluntad sino la tuya, que es ordenada, prudente, justa, infinitamente perfecta en todo sentido. Mi Dios querido, hazme dócil y casto instrumento de tu divina voluntad, que jamás haga lo que yo quiero... Haz que yo me sienta siempre en todo, un miembro, en todo el más humilde del seminario de Yarumal y mire a su fundador ${ }^{54}$ como a mi padre; a sus superiores como los míos; a sus miembros todos como a mis hermanos; a sus reglas como a mi norma de vida; a su gloria como a mi luz, a sus tristezas como castigo de mis pecados. Señor Jesús, perdóname lo mal javeriano que soy y haz que en adelante me convierta en todo lo que tú quieres. ${ }^{55}$

Este seguimiento a la "voluntad del padre" implica renuncias que no son nada fáciles, porque no se trata de renunciar a su voluntad para no hacer nada; todo lo contrario: es hacer, pero desde lo que él considera es la voluntad de Dios. Lo expresa claramente en su oración del 4 de febrero de 1957:

Y ahora hazme comprender, que, pues tú me asistes tan amorosamente, no puedo vivir más en esta turbulencia de preocupaciones que me hacen completamente distraído y me impiden ser dueño de mí mismo para orar y trabajar. Haz que yo cumpla tu divina voluntad a cada instante. Pero no me dejes más vivir en el vicio de creer que mis caprichosas volubilidades sean tu divino querer y que no es posible someterme a mi plan de vida porque el futuro está en tus manos. ${ }^{56}$

Quince años de vida sacerdotal, ¡y todavía en búsqueda del cumplimiento de la "voluntad del Padre"!

\section{Los pobres y la pobreza}

La pasión y obsesión de Valencia no son solo los pobres (indígenas y negros) sino igualmente la pobreza. Esta quinta dimensión de su espiritualidad se ve reflejada en

\footnotetext{
${ }^{53}$ Ibíd., 191.

${ }^{54}$ Aquí se refiere a monseñor Miguel Ángel Builes, fundador de los misioneros de Yarumal. Sirva esta alusión de Valencia Cano para empezar a entender por qué la cercanía y respeto hacia monseñor Builes, con quien tendría profundas distancia políticas y eclesiológicas. Se proponía, en oración, aceptarlo como su padre.

${ }^{55}$ Jaramillo González (ed.), Monseñor Valencia, 171.

${ }^{56}$ Ibíd., 175.
} 
su lema episcopal, cuando es vicario apostólico de Buenaventura, al ser consagrado obispo: "Evangelizare pauperibus misit me Dominus"("El señor me ha enviado a evangelizar a los pobres") 57 .

Su vida es coherente con estos principios, y aunque son diferentes, en el "hermano mayor" se encuentran perfectamente conjugados. Iniciemos con su concepto sobre el pobre. Como ya es costumbre, "Moncho" entiende a los pobres, desde el Evangelio mismo:

Bienaventurados los pobres, porque de ellos es el Reino de los cielos: los pobres, nos decía, son los desposeídos, los abandonados, los impotentes, los pisoteados, los alejados de las oportunidades por el sistema, que en el fondo es nuestro egoísmo encarnado. En ellos vive Cristo con un realismo descarnado, es el pueblo de los pobres. En los pobres está un grupo de hermanos; sin ellos, sin su crecimiento la comunidad andará desequilibrada. La Iglesia no podrá ser signo de unión ante la realidad del mundo. ${ }^{58}$

Este reportaje del jesuita Gabriel Izquierdo muestra con nitidez la dimensión del pobre para Valencia Cano:

Su casa sencilla de Buenaventura se veía llena de gentes de todo el país que llegaban continuamente a visitarlo y a trabajar a su lado: universitarios, profesionales, sacerdotes, investigadores, hombres de negocio, morenos de la costa del Pacífico. Para todos las puertas abiertas, para todos nosotros su casa siempre fue nuestra casa, la casa de sus hermanos, su mesa siempre fue nuestra mesa. ${ }^{59}$

En sus oraciones pide por los pobres, los exalta como personas, pero nunca justifica ni entiende su condición. Escúchese su desconcierto, su suplica:

Yo quiero, mi Dios que no haya gente con hambre. / ¿Por qué no les das de comer? / ¿Qué me pides para que ellos coman? / ¿Acaso el plato que dejo va a saciar a los hambrientos? / ¿¿Señor, acaso se han agotado tus graneros? / Yo quiero que todos coman cuando dicen "pio". Por qué mi Dios eres así?

Es tanta la preocupación del obispo por la condición de la pobreza, y tanto su rechazo a ella, que en 1963 escribe un artículo en la revista Semisiones, en el cual desarrolla su pensamiento al respecto:

El fundador de un instituto, por ejemplo, que cimente el espíritu de su comunidad en la sola pobreza, habrá colocado los cimientos sobre la arena.

\footnotetext{
${ }^{57}$ Valencia Cano, "El señor me ha enviado a evangelizar a los pobres", 2.

${ }^{58}$ Izquierdo, "El hermano que vive entre nosotros", 180-184.

${ }^{59}$ Ibíd.

${ }^{60}$ Valencia Cano, Con Dios a la madrugada, 61.
} 
Amar a los pobres porque son pobres es hacerles perder toda esperanza.

El hambre, la desnudez, la falta de techo, no son de por sí en modo alguno santificadoras.

Pretender que un país desarrollado vuelva a vivir como los indios de los Andes es ir contra la naturaleza.

La Iglesia de Cristo ama el progreso como ama al hombre mismo.

La santidad no se valora en dinero sino en amor universal.

Un gobierno cristiano que frenara al progreso de su pueblo sería casi un traidor.

$\mathrm{Si}$ Jesucristo naciera de nuevo, volvería quizá a nacer en un tugurio, no para divinizar el tugurio sino para hacer resaltar más lo irrazonable de esta miseria.

El mayor pecado del mundo de hoy no es en modo alguno su riqueza sino el hambre de los que no tienen que comer.

El hambre, la desnudez, la ignorancia, la falta de techo son verdaderos males de la humanidad.

Jesucristo no beatificó la despensa vacía sino el ansia de amor.

Cuando la Iglesia prefiere a los pobres no es por lo que les falta sino por lo que tiene que llevarles. ${ }^{61}$

La opción de Valencia Cano por los pobres es igualmente una acción de denuncia contra la pobreza y un llamado a la Iglesia para que asuma este compromiso. $\mathrm{Al}$ continuar con su labor profética, dice en su programa radial "Buenos días Buenaventura”, el 16 de septiembre de 1970, en tono de denuncia:

Las gentes del interior del país, que visitan en Buenaventura los barrios de la marea: Venecia, Santa Mónica, La Playita, Lleras, etc., se quedan pasmadas ante la miseria de estas pobres gentes, que -a más del hambre, la desnudez y el abandono en que viven- tienen que someterse al tormento del relleno de las calles, con la basura que se recoge en la zona $\mathrm{A}^{62}$.

Aquellas pobres gentes no han podido vivir de otro modo: al pantano de la marea le tienen que agregar la basura y la inmundicia para poder caminar. Ayer, nada menos, unas pobres madres de familia lloraban al mirar como la puja ${ }^{63}$ les había robado la basura con que habían rellenado los baches del frente de sus chozas. Mientras en la carretera Buga-Madroñal se derrochaban millones en muros "chimbos" como el de la quebrada Bendiciones, y millares de volquetadas de balasto son arrojadas al monte por las aguas lluvias, estos pobres hermanos nuestros de los barrios de la mares tienen que condimentar su hambre y su desnudez con la basura fétida, que les llevan a buen precio los carros del municipio. ${ }^{64}$

${ }^{61}$ Ídem, “Sobre la pobreza”, 31.

${ }^{62}$ Nota del original: "Zona en la que vive la gente más acomodada".

${ }^{63}$ Nota del original: "Marea alta".

${ }^{64}$ Jaramillo González (ed.), Monseñor Valencia, 147. 
En este documento denuncia a los políticos que hacen campaña con promesas a estas gentes pobres, a organismos gubernamentales como el Instituto de Crédito Territorial, a las aduanas nacionales, a las empresas públicas, a la corrupción "reinante" en todas ellas. Por ello, su espiritualidad está enmarcada por un afán de justicia que, en dimensión profética, debe además anunciar: "Mi consigna: revolución. Las autoridades no deben estar muy tranquilas por más que yo quiera armar una revolución con comulgantes y aunque mi código sea el Evangelio. Podría ser pero por los fanáticos" ${ }^{65}$. El prelado está en consonancia con las orientaciones más avanzadas de la Iglesia. El Sínodo de Obispos realizado en septiembre de 1971 es claro en manifestar:

Percibimos al mismo tiempo un movimiento íntimo que impulsa al mundo desde abajo. En efecto, no faltan hechos que constituyen una contribución a la promoción de la justicia. Nace en los grupos humanos y en los mismos pueblos una conciencia nueva que los sacude contra la resignación al fatalismo y los impulsa a su liberación y a la responsabilidad de su propia suerte. Aparecen movimientos humanos que reflejan la esperanza de un mundo mejor y la voluntad de cambiar todo aquello que ya no se puede tolerar.

Escuchando el clamor de quienes sufren violencia y se ven oprimidos por sistemas y mecanismos injustos; y escuchando también los interrogantes de un mundo que con su perversidad contradice el plan del Creador, tenemos conciencia unánime de la vocación de la Iglesia a estar presente en el corazón del mundo predicando la Buena Nueva a los pobres, la liberación a los oprimidos y la alegría a los afligidos. La esperanza y el impulso que animan profundamente al mundo no son ajenos al dinamismo del Evangelio, que por virtud del Espíritu Santo libera a los hombres del pecado personal y de sus consecuencias en la vida social. ${ }^{66}$

Este afán de justicia lo ratifica Valencia Cano justo pocos días antes de muerte, en su oración del 10 de enero de 1972: “¿Si la necesidad más grave y urgente del mundo de hoy es la justicia, no crees (Gerardo) que tu deber más grave y urgente es trabajar por ella? Ahora, Señor, indícame los modos, los medios y los caminos" ${ }^{67}$. Su principal biógrafo narra una de sus "anécdotas":

Cuando la empresa Puertos de Colombia expulsaba seis mil habitantes de sus barrios lacustres, sin prevención justa y sin construir previamente moradas dignas a donde se pudiera refugiar, sino a la voz de la Draga de Incofrán que vomitaba agua y lodo sobre estos pobres, le vimos con el lodo a la rodilla

\footnotetext{
${ }^{65}$ Ibíd. , 181.

${ }^{66}$ Sínodo de Obispos de 1971, "La justicia en el mundo. Nuevas responsabilidades de la Iglesia en el campo de la justicia. Su misión implica la defensa de los derechos de la persona humana. educación para la justicia”.

${ }^{67}$ Ibíd. , 187.
} 
auxiliando a los necesitados, cargando en sus hombros colchones y tablas, y trasportando girones de miseria en la volqueta del Vicariato. Clamó desde la radio para que no se cometiera la injusticia, pero el eco de la prensa fue... "El obispo de Buenaventura se opone al progreso". ${ }^{68}$

En este mismo sentido, dos años después de su muerte, el diario El Occidente publica un artículo de Emilio Fernández, titulado "Valencia Cano, a dos años de su muerte sigue vivo para su pueblo", en el que -de manera anecdótica- recuerda el compromiso social por la justicia del "hermano mayor":

En cierta oportunidad, dice Rodolfo Suarez, un locutor, hubo una invasión en uno de los sectores del barrio "Muro Yusti". Las autoridades solicitaron la intervención del ejército para desalojar a los invasores. Llamaron a monseñor Valencia y este, para solucionar la situación, les dijo a los jefes de familia de cada rancho: "Alcen en sus respectivas casas la bandera nacional". El ejército no pudo intervenir.

Comenta que cuando en Buenaventura hubo varios disturbios se pidió la intervención del "hermano mayor". Este fue hasta el sitio de los acontecimientos y contuvo a los manifestantes. Dicen que policía que era tocado por Monseñor, no recibía ningún atropello de los participantes en la manifestación. Era como un milagro. ${ }^{69}$

Para concluir este aspecto se transcriben apartes de uno de sus programas radiales en Radio Andagoya, los mismos que transcribió el periódico El Pacifico en edición del mes de junio de 1978, en homenaje al desaparecido obispo:

En un mundo de cambios rápidos que nos obligan a hablar de "una auténtica transformación social y cultural", el sacerdote no es un mudo espectador, sino actor con un papel, quizá más importante que muchos otros profesionales. Y siendo el sacerdote un miembro de la comunidad humana, participante activo de todas sus vicisitudes, es absurdo encerrarlo o encerrarse él dentro del templo como dedicado exclusivamente al culto de Dios. ${ }^{70}$

Su vida de santidad la vive al lado de los pobres. No es opción, sino "exigencia de Dios", la cual acepta y por la cual está dispuesto a dar su vida, si es necesario. Esta opción regula su vida. Nuevamente, dice al respecto en sus oraciones:

Ah, ya comprendo. / No me quieres sacar de entre mis pobres. / ¡Gracias! Acepto así, mi Dios, / acepto con toda mi alma seguir viviendo entre ellos. /

${ }^{68}$ Jaramillo González, "Este obispo es asî”, 30-32. [Estas revistas se encuentran en el archivo de la orden de Misioneros Javerianos (Casa central), en Yarumal, Antioquia].

${ }^{69}$ Fernández, "Valencia Cano, a dos años de su muerte sigue vivo para su pueblo".

${ }^{70}$ El Pacífico, "El sacerdote y el cambio social, según monseñor Valencia Cano”. 
Renuncio por su amor a las riquezas con las que ben... ${ }^{11} /$...ces a los santos, que les permiten gustar sabrosamen... ${ }^{72} /$ de tu mesa, vestirse de sus galas, pasearse con los $[\ldots]^{73}$ os / Déjame a mí con mis pobres, Con tus pobres; / sintiendo sus angustias y las tuyas. / Ellos porque no te tienen y tú por que no los tienes. / Déjame en sus sombras, déjame en sus fatigas, déjame en sus luchas. / Para que todos crean que siendo de los suyos, los / compadezco con sinceridad; / déjame seguirlos, como tú los seguiste y los sigues / Aún "hecho pecado" para salvarlos. ${ }^{74}$

Valencia Cano cree firmemente que su misión es ayudar a los pobres a toda costa. Más que un propósito natural, siente que esta es la voluntad de Dios:

Soy un obispo del pueblo de Dios ${ }^{75}$. Tengo que ser fiel a Cristo que me ha elegido para decirle a los pobres que él existe. La fidelidad a Cristo me obliga a ser fiel a los hombres. Por eso nadie ni nada me impedirá seguir diciendo: la salvación está en Cristo encarnado y hecho realidad en la vida de los hombres. ${ }^{76}$

Su preocupación por los pobres, naturalmente, se encuentra relacionada de manera intrínsica con su fidelidad y vocación de seguimiento a Dios; es decir, su espiritualidad pasa necesariamente por un camino al lado de los pobres, por el cual opta inequívocamente.

\section{La amada pobreza}

Paradójicamente crítico de la pobreza, aunque amante y seguidor de los pobres, Valencia Cano asume personalmente el ideal de pobreza como camino de santidad. Se encuentran sinnúmero de referencias que ratifican esta perspectiva, desde sus oraciones, escritos y testimonios, que han acopiado personas que vivieron cerca de él.

Los propósitos de humildad y pobreza, en el obispo, están igualmente marcados por un camino espiritual de abstinencia, de martirio, de renuncia. En su oración del 25 de febrero de 1948, antes de iniciar su obra misionera en Vaupés, cuando ya es profesor en el seminario de Yarumal, pide al "padre" mayores fuerzas para una mejor consagración. Parece prepararse para la prefectura que le será asignada un año después:

Haz que te ame con mayor generosidad, de tal modo que nada te niegue, y corra, sí, corra tras el olor de tu sangre. ¿Qué importa que no perciba tus perfumes? Sigue dulcísimo Jesús, siendo manojito de mirra para mí; tú embriagas,

\footnotetext{
${ }^{71}$ Ilegible en el original.

${ }^{72}$ Inconcluso en el original.

${ }^{73}$ Ilegible en el original.

${ }^{74}$ Osorno, "20 años de resurrección y profecía", 5-7.

${ }^{75}$ Es clara alusión a la definición eclesiológica del Concilio Vaticano II.

${ }^{76}$ Osorno, "20 años de resurrección y profecía", 5-7.
} 
aunque no sea con dulzura y hechizas aún con tus heridas. Jesús mío, rey mío, amor único mío, átame a tu cruz. Con clavos remachados, allí quiero vivir, morir y amarte eternamente. Amén. ${ }^{77}$

Este es un camino que implica sacrificios: “...te prometo no darme gusto jamás, y no negarte jamás nada, aunque me pidas el sacrificio de mi vida”. Esta es una opción de vida para la que está dispuesto y pide al "padre" ayuda para poder cumplirla:

No permitas, te lo ruego encarecidamente, que me desvíe por malicia o por torpeza, ni que retarde el medidor de carrera para excusar mi debilidad. Haz que camine por donde tú quieres, como tú quieres y mientras tú lo quieras, en la realización más perfecta del programa que "ab aeterno"te has forjado para mí en este día y en todo el resto de mi vida. Ayúdame a vencer el sueño, la pereza, la gula, la lujuria y la soberbia que son mis vicios capitales. ${ }^{78}$

Sin embargo, escúchense ahora las propias palabras de monseñor Valencia Cano, quien en Guayaquil, en 1958, escribe emocionado en su oración:

Dios mío, gracias por esta divina luz. Haz que yo comprenda mejor mi vocación de viajero, y que en vez de querer viajar como los grandes gerentes o embajadores, ambicione imitar a Jesús, María y José, imitar al divino Maestro, sin techo ni almohada, ni alforja; imitar al gran San Pablo y a Javier. Solo viviendo tu santa pobreza mi dulce Jesús, podré cosechar el fruto que ambiciono y mantener mi unión contigo. ${ }^{79}$

En este mismo viaje a Guayaquil, para participar en un congreso de misiones, al verse rodeado de buenas atenciones y buena comida, pide a Dios en su oración que comprenda mejor su vocación de viajero y al no querer viajar como los grandes se hace el siguiente propósito coherente con su opción de vida:

Propósito: jamás quejarme de las incomodidades de un viaje: cansancio, mal servicio, varadas, inclemencias del tiempo, largas esperas. Estar con mucha modestia: vehículos, hoteles, personas importantes. Jamás hacer gastos inútiles. Ofrecerme siempre como servidor de los compañeros. Cumplir estrictamente con mis ejercicios de piedad. Mantener mortificados los sentidos. Aprovechar toda ocasión para ejercitar mi ministerio sacerdotal, pastoral y catequístico. ${ }^{80}$

Antonio Buitrago, uno de sus más cercanos colaboradores en Mitú y también misionero javeriano de Yarumal, ha escrito en unas pocas páginas un "Anecdotario del hermano Gerardo". En ellas insiste en esta dimensión de pobreza que se ha venido desarrollando:

\footnotetext{
${ }_{77}$ Jaramillo González (ed.), Monseñor Valencia, 167.

${ }^{78}$ Ibíd., 173

${ }^{79}$ Ibíd., 176.

${ }^{80}$ Ibíd.
} 
- ¿Y sus zapatos Monseñor?- preguntaron las hermanas al verlo llegar descalzo después de un fatigoso viaje por la trocha selvática de Monfort a Villa Fátima.

-Se me perdieron- fue su única respuesta. Dame unos del almacén, agrega, y entre varios pares que se midió, dejó para sí unas botas tennis no muy elegantes para un prelado, pero que sí corrían parejas con el estilo del hermano Gerardo, poco amigo de sotanas encarnadas, adornos lustrosos y zapatos con hebillas.

[...] en una de sus visitas al seminario de Yarumal, instituto al cual fue fiel hasta el último día, se presentó sin solideo, ni atuendos morados; tampoco llevaba anillo episcopal. Como alguno le preguntara: "Monseñor, y el anillo qué lo hizo?" Sacándolo de la relojera de la sotana, en donde lo tenía en una pequeña caja de fósforos, le contestó al interlocutor: "Aquí esta, vos".

Luego prescindió también de la caja de fósforos, de la relojera, de la sotana y por supuesto del anillo. ${ }^{81}$

Continúa el hermano Antonio en su anecdotario:

"Dame un peso para pagar el bus" era una de las peticiones que a menudo hacía monseñor Valencia a sus feligreses. El obispo iba a pie a varios lugares, y cuando ya estaba cansado, dándose cuenta que no había llevado dinero, pedía ayuda a sus hermanos negros.

Almorzando con un amigo en uno de los restaurantes de Buenaventura, un moreno le pidió "la caridad de Dios". Él se levantó y le cedió el puesto al necesitado, comentando: "Quizás desde ayer no come este pobre moreno".

En el año pasado [1966] hubo necesidad de facilitarle por 17 veces el colchón para su cama, porque otras tantas lo había regalado. ${ }^{82}$

Su pobreza está acompañada de "humildad y sencillez", anota sorprendido su compañero de comunidad, Antonio Buitrago:

Una vez le dije: Monseñor, ¿̨usted por qué no se pone una sotana siquiera para esas reuniones a las que le toca asistir con gente de tacón alto, para que no se haga tan notorio? Él me contestó: "Oí hermanito, a mí ya todos me conocen así; si me la pongo me vuelvo más notorio, ¿no te parece?” ${ }_{83}$

O cuando se refiere a su actividad cotidiana:

El hermano Gerardo arreglaba personalmente su cama y embolaba sus zapatos. Una vez llegó con los zapatos embarrados y un hermano, para congraciarse con él, se ofreció para limpiárselos. Monseñor le dijo: "No me dejé embolar de mi mamá, menos de vos". ${ }^{84}$

\footnotetext{
${ }^{81}$ Buitrago, "Anecdotario del Hermano Gerardo", 252.

${ }^{82}$ Ibíd., 259.

${ }^{83}$ Ibíd., 252.

${ }^{84}$ Ibíd., 260.
} 
Es en su oración, desde su propio sentimiento, que se descubre en él esa profunda necesidad de hacerse pobre con los pobres:

...cuantas veces he querido identificarme con ellos en un todo. Si ser totalmente indio [...] o negro de mis ríos. Tú mismo te has visto en aprietos para detenerme. Ah, ¿y mi sacerdocio? Lo comprendo: ser un sacerdote indio de los indios o negro de los negros. Cuando estuve entre los blancos fui un sacerdote blanco de los blancos. Ahora es mi problema: ¿Cómo dejar de ser blanco? ${ }^{85}$

El ya citado padre jesuita Gabriel Izquierdo, quien pasó unos días en Buenaventura acompañando a monseñor Valencia, testimonia una anécdota del obispo para mostrar sus acciones radicales de desprendimiento:

La necesidad cristiana de compartirlo todo para que los que sean menos sean más, y todos crezcamos, se expresaba en monseñor Valencia de una manera increíble. Una tarde húmeda y lluviosa caminábamos por Buenaventura, cuando un moreno viejo y triste se acerca a Monseñor y le pide ayuda para conseguir zapatos. Monseñor, con un gesto sencillo, antidemagógico, casi imperceptible, se quitó sus zapatos y se los entregó. ${ }^{86}$

Testimonios como este se hallan en abundancia. El principal biógrafo de Valencia Cano, compañero de congregación, dirá en una microbiografía publicada por la revista de los misioneros de Yarumal, Semisiones, en 1968: "Es dadivoso hasta el desorden, todo lo da. No usa solideo, ni pectoral, ni anillo, ni banda” ${ }^{87} \mathrm{Y}$ con profunda admiración comenta sobre el hermano-obispo Valencia:

Un día arrancó las cortinas que le pusieron, en una ausencia, en las ventanas de su despacho. La mesa de su despacho episcopal es como un pupitre de estudiante pobre. El tapiz [...] apenas es suficiente para la mesita de centro: mide cincuenta centímetros por ochenta. Su pectoral es una crucecita de madera que bien luciría en el pecho de un niño de primera comunión. No quiere más arreos episcopales: el armińo lo regaló (entero) y la capa magna, con su cauda, la repartió entre varios pobres. Su excelencia, quien no quiere que se le diga más excelencia sino el hermano mayor, ha dicho que al dar estas cosas a los pobres tenía que partirlas para que les tocara a varios. ${ }^{88}$

Al evaluar su existencia, se reconoce al obispo angustiado por no haber logrado ser identificado como "uno de ellos". "A mí, por más que camine a pie por los barrios,

\footnotetext{
${ }^{85}$ Jaramillo González (ed.), Monseñor Valencia, 190-191.

${ }^{86}$ Izquierdo, "El hermano que vive entre nosotros".

${ }^{87}$ Jaramillo González, “Este obispo es asî”, 30-32.

${ }^{88}$ Ibíd.
} 
todavía me dicen “excelencia”" "99. Dos días antes de su muerte, en una súplica a su padre, manifiesta: "Señor Jesús, enséńame la humildad, la mansedumbre y el amor necesarios para hacer lo que quieres de mí" ${ }^{\prime \prime}$.

Con este último pensamiento se cierra el círculo que se abrió en este artículo. Gerardo Valencia Cano, el obispo de los pobres en Colombia y el amigo cercano de dom Hélder Câmara, conocido igualmente en América Latina como el "obispo rojo", quiere hacer en su vida "la voluntad de Dios"; y esa voluntad del "padre" la asume siendo pobre entre los pobres, camino de santidad marcado por su referente espiritual, el padre Carlos de Foucault, cuyo lema es "ser pobre entre los pobres".

Después de su muerte, en el trágico accidente aéreo del 21 de enero de 1972, el diario del padre Ricardo Saldarriaga ${ }^{91}$ sintetiza la "presencia" del obispo:

Enero 27. Hoy han desistido del rescate: es imposible descender al lugar donde quedaron sepultadas las víctimas. Monseñor Valencia, desde su niñez, soñó en la selva al lado de los más humildes y marginados. Ahora... ¿se quedará sepultado en la selva? Su deseo será cumplido, pero Buenaventura ora, clama y se impacienta hasta que sea rescatado su pastor. ${ }^{92}$

\section{Conclusiones}

La espiritualidad, dimensión que ha sido abordada en este texto, tiene matices teológicos e históricos. Las líneas anteriores denotan el esfuerzo por guardar fidelidad al pensamiento de Gerardo Valencia Cano. De ahí que se ha dejado hablar fundamentalmente al obispo en sus oraciones, discursos y poemas. Como se ha podido evidenciar, la espiritualidad de Valencia Cano supone la articulación de distintas características, en este caso, de cinco variables (la santidad, el recogimiento, la oración, el abandono a la voluntad de Dios y la pobreza) que delinearon poco a poco su quehacer apostólico, todas ellas articuladas por la fe.

Como el artículo sugiere, la comunión con Dios es el punto de partida y el andamiaje de la obra del obispo Valencia Cano, quien tuvo un profundo sentido de la presencia de Dios, como aparece de manera reiterada en sus oraciones.

La gran consecuencia del cristianismo del obispo Valencia es su profundo humanismo, el cual pasa necesariamente por una gran compasión, la pasión con el otro, el próximo, el necesitado, hace que sienta con los demás alegrías, tristezas y necesidades.

\footnotetext{
${ }^{89}$ Ibíd., 188.

${ }^{90}$ Ibíd., 191.

${ }^{91}$ Sacerdote antioqueño que dirigió el rescate del obispo tras el accidente aéreo que le costó la vida.

${ }^{92}$ Ibíd.
} 
Plasmó el espíritu cristiano en formas concretas de vivir y relacionarse en sociedad. No se lo puede entender únicamente desde lo socioeconómico y lo político, pues sería mutilarlo. Su espiritualidad es una clave imprescindible para su comprensión.

Entrometerse en sus oraciones y poemas hace posible encontrar entonces el génesis de su obra. Es desde la espiritualidad donde puede entenderse la devoción e inclinación del "obispo por los pobres". Se presenta entonces un prelado sumamente noble, no solo con las personas que lo circundaban sino con Dios. Monseñor hablaba mucho de sí mismo en sus testimonios, pero casi siempre para resaltar sus limitaciones y dificultades. Sus oraciones permiten ver la efervescencia espiritual abierta de par en par en sus escritos.

Aunque está en discusión si el papel de Valencia Cano en el movimiento sacerdotal Golconda es protagónico ${ }^{93}$, sí está claro que el "hermano mayor" se inscribe en la hipótesis fundacional de la teología de la liberación desarrollada por Gustavo Gutiérrez. “...cómo hablar de Dios al pobre, al no persona, al no humano...” ${ }^{44}$. Su opción por los pobres guiará su espiritualidad, su compromiso y su testimonio.

Concluimos con Jaime García, quien sostiene: "A Gerardo, por su praxis testimonial, por su pensamiento crítico y agudo sobre la realidad y por su mensaje pleno de esperanza cristiana, se le puede considerar como un precursor insigne de la nueva teología de la liberación" 95 .

\section{Bibliografía}

Asociación Carlos de Foucauld en España. "Carlos de Foucauld, 1858-1916". Carlos de Foucauld, http://www.carlosdefoucauld.es/HnoCarlos/biografia.htm (consultado el 15 de diciembre de 2015).

Betancourt Echeverri, Darío y Martha García. Matones y cuadrilleros. Origen y evolución de la violencia en el occidente colombiano. Bogotá: Universidad Nacional- Tercer Mundo, 1990.

Buitrago, Antonio. "Anecdotario del hermano Gerardo". En Monseñor Valencia, editado por Gerardo Jaramillo González, 249-261. Bogotá: Librería Estella, 1972.

Calvo Isaza, Óscar y Mayra Parra Salazar. Medellin (rojo) 1968. Medellín: Planeta, 2012.

\footnotetext{
${ }^{93}$ Larosa, De la derecha a la izquierda. La Iglesia Católica en la Colombia contemporánea, 225; Calvo Isaza y Parra Salazar, Medellin (Rojo) 1968, 170.

${ }^{94}$ Gutiérrez, Teología de la liberación. Perspectivas, 199-200.

${ }^{55}$ García, Jaime, Cristianos por la liberación en Colombia. Algunos aportes más significativos en el caminar histórico, 76.
} 
Celam. "II Conferencia General del Episcopado Latinoamericano. Documentos finales de Medellín”. Jesuitas-CPAL, http://www.cpalsj.org/wp-content/ uploads/2013/03/Medellin-II_CELAM-ESP.pdf (consultado el 4 de enero de 2016).

Conferencia Episcopal de Colombia. Conferencias Episcopales de Colombia. Tomo I: 1908-1953. Bogotá: El Catolicismo, 1956.

De Foucauld, Carlos. "Oración del abandono". Carlos de Foucauld, http://www. carlosdefoucauld.org/para-orar/oracion-del-abandono (consultado el 17 de diciembre de 2015).

De Roux, Rodolfo Ramón. "Religión y revolución". En Presencia de la Iglesia en América Latina, I Simposio sobre la Presencia de la Iglesia en América Latina, noviembre de 1985. Bogotá: Pontificia Universidad Javeriana 1985.

Echeverry Pérez, Antonio José. Echeverry, Gerardo Valencia Cano. Un profeta invisibilizado. Cali: Universidad del Valle-Unicatólica, 2017.

- Teología de la liberación en Colombia, un problema de continuidades en la tradición evangélica de opción por los pobres. Cali: Universidad del Valle, 2005.

El Pacífico. "El sacerdote y el cambio social según monseñor Valencia Cano". Diario El Pacifico, Buenaventura, día de junio de 197. [Consultado en el Archivo de la Diócesis de Buenaventura].

Fernández, Emilio. "Valencia Cano, a dos años de su muerte sigue vivo para su pueblo". Diario El Occidente, Cali, 21 de enero de 1974, 3. [Consultado en: Diario El Occidente, 1964-1974. Hemeroteca de la Biblioteca Departamental Jorge Garcés Borrero].

Fondo Acumulado. Folleto "Monseñor Gerardo Valencia Cano". s/c: Comité de relaciones IMEY, 1983. [Consultado en el Archivo del Vicariato Apostólico de Mitú].

García, Jaime. Cristianos por la liberación en Colombia. Algunos aportes más significativos en el caminar histórico. Bogotá: Asociación de Teólogos de Colombia- Koinonia, 1992.

Gutiérrez, Gustavo, Teología de la liberación. Perspectivas. Lima: CEP, 1971.

Hobsbawm, Eric. Historia del siglo XX. Buenos Aires: Crítica-Grijalbo Mondadori S.A, 1994.

Izquierdo, Gabriel. "El hermano que vive entre nosotros. Monseñor Gerardo Valencia Cano”. Revista Javeriana Vol. LXXVII, No. 382 (1972): 180-184. 
Jaramillo González, Gerardo. El obispo de los pobres: una biografía de monseñor Gerardo Valencia Cano. Medellín: Seminario de Misiones Extranjeras de Yarumal, 2008. . "Este obispo es asî". Revista Semisiones 138 Vol. 21 (1967): 30-32. (ed.). Monseñor Valencia. Bogotá: Talleres Editoriales de la Librería Stella, 1972.

Larosa, Michael. De la derecha a la izquierda. La Iglesia Católica en la Colombia contemporánea. Bogotá: Planeta, 2000.

Muniproc. Golconda, el libro rojo de los "curas rebeldes". Bogotá: Cosmos, 1969.

Osorno, Emilio Jesús. "20 años de resurrección y profecía”. Revista Misioneros de Yarumal (1992): 5-7.

Pio XI. "Carta encíclica Divini Redemptoris sobre el comunismo ateo (1937)". Vatican, https://w2.vatican.va/content/pius-xi/es/encyclicals/documents/hf_p-xi_ enc_19370319_divini-redemptoris.html (consultado el 20 de junio de 2014).

Restrepo, Javier Darío. La revolución de las sotanas. Golconda 25 años después. Bogotá: Planeta, 1995.

Rojas, Diana Marcela. "Alliance for Progress in Colombia”. Análisis politico Vol. 23, No. 70 (2010): 91-124. Disponible en: Universidad Nacional de Colombia, http://revistas.unal.edu.co/index.php/anpol/article/view/45595 (consultado 13 de mayo de 2014).

Rueda Palta, José Olinto. "El campo y la ciudad: Colombia, de un país rural a país urbano”. En Credencial historia 119 (1999). Disponible en: Biblioteca Virtual Banco de la República, http://www.banrepcultural.org/node/32860 (consultado el 25 de febrero de 2014).

Sínodo de Obispos de 1971. "La justicia en el mundo. Nuevas responsabilidades de la Iglesia en el campo de la justicia. Su misión implica la defensa de los derechos de la persona humana. educación para la justicia”. Mercabá, http://www. mercaba.org/SINODOS/1971_la_justicia_en_el_mundo.htm (consultado el 17 de marzo de 2016).

Valencia Cano, Gerardo. Con Dios a la madrugada. Bogotá: Tercer Mundo, 1965. . "El señor me ha enviado a evangelizar a los pobres". Diario El Colombiano, Medellín, 26 de mayo de 1953, 2.

. "Sobre la pobreza”. Revista Semisiones 115, Vol. 4 (1963): 31. 